\title{
Nonmalignant Respiratory Disease Mortality Among Woodworkers Participating in the American Cancer Society Cancer Prevention Study-II (CPS-II)
}

\author{
Paul A. Demers, PhD, ${ }^{1,2 *}$ Steven D. Stellman, PhD, MPH, ${ }^{3}$ Didier Colin, MSc, $^{2}$ \\ and Paolo Boffetta, MD, MPH ${ }^{2}$
}

\begin{abstract}
Nonmalignant respiratory disease (NMRD) mortality was examined among woodworkers participating in the American Cancer Society's CPS-II cohort study. During the 6-year prospective follow-up, there were 97 NMRD deaths among 11,541 men reporting employment in wood-related occupations and 1,338 NMRD deaths among 317,424 men reporting no exposure to wood dust or wood-related jobs. Relative risks, adjusted for age and smoking, were calculated using Poisson regression. A small excess of NMRD was observed among woodworkers. However, the relative risk was higher among woodworkers who did not report exposure to wood dust $(R R=1.52,95 \% C I=1.18-1.97)$ than those who did $(R R=1.27$, $95 \% C I=0.91-1.77)$, and no clear trend with duration of exposure was observed. An excess of NMRD was observed among woodworkers reporting exposure to asbestos $(R R=1.59,95 \%$ $C I=0.85-2.96)$, as well as the small number of woodworkers reporting exposure to formaldehyde $(R R=1.95,95 \% C I=0.63-6.06)$, but men not reporting exposure to these substances also had an excess risk. Although limited by a short follow-up period and crude indicators of exposure, the strengths of this analysis were the ability to compare woodworkers to a similar, healthy population and to adjust for the effects of smoking. Cohort studies with better exposure information are needed to examine the role of occupational exposures among woodworkers in the etiology of respiratory disease. Am. J. Ind. Med. 34:238-243, 1998. (1) 1998 Wiley-Liss, Inc.
\end{abstract}

KEY WORDS: respiratory disease; occupational diseases; woodworkers; wood dust; asbestos; formaldehyde

\footnotetext{
${ }^{1}$ Occupational Hygiene Program, University of British Columbia, Vancouver, Canada

2Unit of Environmental Cancer Epidemiology, International Agency for Research on Cancer, Lyon, France

${ }^{3}$ Division of Epidemiology, American Health Foundation, New York, New York

This paper was presented at the 25th meeting of the International Congress on Occupational Health, Stockholm, Sweden, September 15-20, 1996. The work reported here was partially undertaken during the tenure of a Research Training Fellowship awarded to Paul Demers by the International Agency for Research on Cancer

Contract grant sponsor: the American Cancer Society; Contract grant number: R-9201; Contract grant sponsor: the U.S. National Cancer Institute; Contract grant numbers: CA-32617 and CA-68384; Contract grant sponsor: the European Commission; Contract grant numbers: 91-CV V-E 2015-E and 92-CV V-E 2001-0

*Correspondence to: Paul A. Demers, PhD, Assistant Professor, Occupational Hygiene Program, University of British Columbia, 2206 E. Mall, 3rd Floor, Vancouver, BC V6T 1Z3, Canada. E-mail: pdemers@unixg.ubc.ca
}

Accepted 20 March 1998

(c) 1998 Wiley-Liss, Inc.

\section{INTRODUCTION}

Employment in wood-related industries has been associated with a variety of respiratory diseases, including bronchitis, asthma, extrinsic allergic alveolitis, and chronic airflow obstruction [Chan-Yeung and Malo, 1995]. The primary epidemiologic evidence has come from cross-sectional studies of workers in sawmills and furniture factories in which an increased prevalence of respiratory symptoms and decreased pulmonary function have been observed [Enarson and Chan-Yeung, 1990; Goldsmith and Shy, 1988; Demers et al., 1997a]. Extrinsic allergic alveolitis has been associated with exposure to molds and bacteria, but other respiratory health effects have generally been attributed to wood 
dust exposure. However, the exposure assessment performed in these studies has been limited and some woodworkers may also have been exposed to other potential respiratory hazards either of human origin, such as formaldehyde and asbestos, or of natural origin, such as bioaerosols and the volatile components of wood.

In contrast to the results of cross-sectional studies, industry-based cohort studies of woodworkers have rather consistently observed standardized mortality rates that are less than or equal to that of the general population. For example, in a reanalysis of five cohorts of workers from wood-related industries, the standardized mortality ratio (SMR) for NMRD for all five cohorts combined was 0.81 (95\% CI $=0.75-0.87$ ) [Demers et al., 1995]. The SMRs for the participating cohorts ranged from 0.50 , among the U.S. wood model makers, to 0.90, among the British furniture makers [Demers et al., 1997b; Acheson et al., 1984; Roscoe et al., 1992]. No association between wood dust and NMRD mortality was observed within any of the participating studies or in the pooled analyses [Demers et al., 1995, 1997b].

There are several potential explanations for this apparent discrepancy. It may be that many of the respiratory health effects reported are reversible, or at least are not serious enough to result in increased mortality. In addition, the diseases that are known to have serious long-term effects, such as extrinsic allergic alveolitis and asthma, may be rare enough among woodworkers that they do not affect mortality rates. There may also be selection against continued employment of workers with those conditions who enter the industry. Alternatively, it may be that the difference in the results is due to differences in study design. Specifically, the cross-sectional studies generally used other working populations as comparison groups, have adjusted for the effects of smoking, and have often excluded groups such as office workers from the "exposed" study group. The industrybased cohort studies conducted thus far have compared mortality among woodworkers to the general population and have generally had very little information regarding occupational exposures or smoking.

In 1982, the American Cancer Society initiated a large cohort study to identify risk factors for cancer in the United States, including occupational history, occupational exposures, and smoking. Participants were prospectively followed for mortality for 6 years. The objectives of the present analysis are to examine the risk of death due to NMRD among woodworkers who participated in the American Cancer Society study and to examine the role of exposure to wood dust, formaldehyde, and asbestos. The results of analyses examining the risk of cancer among woodworkers and other persons reporting exposure to wood dust are published in a separate paper [Stellman et al., 1998].

\section{POPULATION AND METHODS}

Both the exposed and comparison populations for this analysis were drawn from participants in the American Cancer Society's (ACS) Cancer Prevention Study - II (CPS-II), details of which have been previously reported [Stellman and Garfinkel, 1986; Stellman et al., 1988]. To summarize, in 1982 more than 77,000 volunteer "researchers" enrolled 509,000 men and 677,000 women in all 50 states, the District of Columbia, and Puerto Rico. The study participants were friends, neighbors, or relatives of the volunteers. Enrollment was in family groups, with at least one person above the age of 45 in each family. All family members 30 years or older were asked to complete a four-page confidential questionnaire on history of cancer and other diseases; body weight and height; exercise; occupations and occupational exposures; and personal habits such as drinking, smoking, and diet.

Every second year, the volunteer "researchers" were given lists of persons whom they enrolled and asked to check whether they were alive or dead, and if dead, the date and place of death. Copies of death certificates were obtained from state health departments and coded to the 9th revision of the International Classification of Diseases (ICD-9). For about one-quarter of reported cancer deaths, inquiry was made through cancer registries, physicians, or hospitals to verify the primary site of diagnosis. The present analysis is restricted to male subjects who were traced through August, 1988 (maximum 72 months); for this group, follow-up was $98 \%$ complete.

Occupations and exposure were determined in separate questions [Stellman et al., 1988]. Occupation was ascertained via a combination of three questions: current occupation, last occupation if retired, and occupation held for the longest period of time. Exposure was reported via a checkoff list of 12 distinct hazards that included, among others, asbestos, coal tar pitch or asphalt, coal or stone dust, formaldehyde, and ionizing radiation. Duration of each exposure was also requested.

The study population consisted of men who reported a wood-related occupation (e.g., carpenter; lumber worker; furniture maker, repairer, or finisher; logger; sawmill operative; woodworker; or woodcutter) as their current, last, or longest-held job. The comparison group consisted of persons who had not reported previous employment in a wood-related job and responded "no" to the wood dust exposure question. A second comparison group consisting of all men who had reported employment in "blue collar" occupations was also created. All persons who reported employment in occupational groups which were included under "precision production, craft, and repair" or "operators, fabricators, or laborers" under the International Standard Classification of Occupations [ILO, 1969] were included in this group. Wood dust was the primary exposure of 
interest in this study, but two other exposures, asbestos and formaldehyde, which are often reported as being common among woodworkers, were also analyzed.

Six categories of respiratory disease were available in the CPS-II dataset: pneumonia and influenza (International Classification of Disease, 9th revision [ICD-9] codes 480 489), bronchitis (490-491), emphysema (492), asthma (493), chronic obstructive lung disease, not elsewhere classified (496), and all other respiratory disease (460-478, 494-495, 500-519). For the purposes of this analysis, a composite category was created to encompass the obstructive lung diseases: bronchitis, emphysema, asthma, and chronic obstructive lung disease, not elsewhere classified (490-493, 496). A similar categorization, chronic nonspecific lung disease, has been proposed and used elsewhere to examine occupational risk factors [Post et al., 1994; Sluiter et al., 1991].

The analysis was restricted to men for whom occupation and exposure data and smoking histories were available. An individual was considered at risk from September, 1982, through date of death or August, 1988. Persons with missing vital status were excluded from the analysis. Rate ratios (RRs) were calculated using maximum likelihood methods [Breslow and Day, 1987]. Approximate 95\% confidence limits are reported, based on the standard error of the coefficients derived from the Poisson regression model. Poisson regression was also used to analyze the relation between respiratory disease risk and duration of wood dust exposure. All analyses were adjusted for age and smoking status using five age groups (30-49, 50-59, 60-69, 70-79, $80+$ ) and four smoking categories (never, past, current, missing). In preliminary analyses, adjustment for age and smoking using more detailed classifications did not alter the estimates appreciably from those using less detailed classifications. All variables were treated in a categorical fashion. Poisson regression analyses were performed using EGRET statistical software (Statistics and Epidemiology Research, Seattle, WA).

Although this study was prospective in nature, the 6-year follow-up period is comparatively short. Chronic respiratory diseases may manifest itself many years before death occurs, creating the potential for differential recall of exposure among ill participants. A question regarding current health status ("Are you sick at the present time?") was included as part of the study. The response to this query was strongly predictive of subsequent mortality. In order to assess the potential impact of health status at the time of the survey on the reporting of exposure, analyses were repeated after introduction of an indicator variable $(1=$ yes, $0=$ otherwise) based on the response to this question.

\section{RESULTS}

A total of 11,541 men reported having worked in wood-related occupations. This group contributed 65,487
TABLE I. Non-Malignant Respiratory Disease Mortality Among Woodworkers; American Cancer Society Cancer Prevention Study II

\begin{tabular}{|c|c|c|c|}
\hline \multirow{2}{*}{$\begin{array}{l}\text { Cause of death } \\
\text { (ICD- } 9 \text { codes) }\end{array}$} & \multicolumn{2}{|c|}{ Observed deaths } & \multirow[b]{2}{*}{$\mathrm{RR}^{*}(95 \% \mathrm{Cl})$} \\
\hline & Woodworkers & Reference & \\
\hline All causes & 1,271 & 22,994 & $1.17(1.11-1.24)$ \\
\hline \multicolumn{4}{|l|}{ All respiratory disease (460- } \\
\hline 519) & 97 & 1,338 & $1.42(1.15-1.74)$ \\
\hline \multicolumn{4}{|l|}{ Pneumonia, influenza (480- } \\
\hline 489) & 27 & 384 & $1.30(0.88-1.92)$ \\
\hline \multicolumn{4}{|l|}{ Obstructive lung disease } \\
\hline$(490-493,496)$ & 52 & 726 & $1.45(1.09-1.92)$ \\
\hline Bronchitis (490-491) & 0 & 34 & 0.00 \\
\hline Emphysema (492) & 14 & 160 & $1.88(1.09-3.25)$ \\
\hline Asthma (493) & 2 & 21 & $2.08(0.49-8.95)$ \\
\hline \multicolumn{4}{|l|}{$\begin{array}{l}\text { Chronic obstructive lung } \\
\text { disease, not otherwise }\end{array}$} \\
\hline classified (496) & 36 & 511 & $1.40(1.00-1.97)$ \\
\hline \multicolumn{4}{|l|}{ Other respiratory (460-468, } \\
\hline $494,495,500-519)$ & 18 & 228 & $1.54(0.95-2.49)$ \\
\hline
\end{tabular}

*Relative risk and confidence intervals are derived from Poisson regression and are adjusted for age and smoking status. The reference population is composed of 317,424 male study participants who did not report employment in a wood occupation or regular exposure to wood dust.

person-years of follow-up, with 1,271 deaths observed. The reference population ("non-woodworkers") consisted of 317,424 men who reported neither working in a woodrelated occupation nor exposure to wood dust; this group contributed 1,839,274 person-years with 22,994 deaths observed. Table I presents the total number of deaths and the number of deaths due to respiratory disease among the woodworkers and the reference group, as well as the rate ratios derived from the Poisson regression models. A small excess of deaths due to all causes was observed among the woodworkers $(\mathrm{RR}=1.17,95 \% \mathrm{CI}=1.11-1.24)$. $\mathrm{A}$ somewhat larger excess of NMRD was observed $(\mathrm{RR}=$ $1.42,95 \% \mathrm{CI}=1.15-1.74)$ and the RRs for all specific respiratory disease categories were elevated, with the exception of bronchitis. However, mortality due to all causes $(\mathrm{RR}=1.06,95 \% \mathrm{CI}=0.99-1.12)$ and $\mathrm{NMRD}(\mathrm{RR}=1.15$, 95\% CI $=0.91-1.44)$ among woodworkers was only slightly elevated when compared to mortality among other "blue collar" workers. In the blue collar comparison, the risk for obstructive lung disease $(\mathrm{RR}=1.24,95 \% \mathrm{CI}=$ $0.90-1.70)$ and other respiratory diseases $(\mathrm{RR}=1.15,95 \%$ $\mathrm{CI}=0.67-1.96)$ remained somewhat elevated, while no excess of pneumonia and influenza $(\mathrm{RR}=1.00,95 \% \mathrm{CI}=$ $0.65-1.54)$ was observed. Only two fatal cases of asthma were observed, while no fatal cases of bronchitis occurred during the follow-up period. 
TABLE II. Non-Malignant Respiratory Disease Mortality Among Woodworkers by Self-Reported Exposure*

\begin{tabular}{lcccc} 
Exposure/cause of death & Observed & $\begin{array}{c}\text { Exposed } \\
\text { RR (95\% Cl) }\end{array}$ & Observed & $\begin{array}{c}\text { Not exposed } \\
\text { RR (95\% Cl) }\end{array}$ \\
\hline Wood dust & & & & \\
All causes of death & 569 & $1.16(1.07-1.27)$ & 702 & $1.18(1.10-1.27)$ \\
All respiratory disease & 36 & $1.27(0.91-1.77)$ & 61 & $1.52(1.18-1.97)$ \\
Pneumonia \& influenza & 9 & $1.12(0.58-2.17)$ & 18 & $1.40(0.87-2.24)$ \\
Obstructive lung diseases & 22 & $1.43(0.94-2.19)$ & 30 & $1.46(1.01-2.10)$ \\
Other respiratory diseases & 5 & $1.02(0.42-2.48)$ & 13 & $1.96(1.12-3.44)$ \\
Asbestos & & & & \\
All causes of death & 144 & $1.28(1.09-1.51)$ & 1,127 & $1.16(1.09-1.23)$ \\
All respiratory disease & 10 & $1.59(0.85-2.96)$ & 87 & $1.43(1.15-1.77)$ \\
Pneumonia \& influenza & 2 & $1.20(0.30-4.80)$ & 25 & $1.36(0.90-2.04)$ \\
Obstructive lung diseases & 6 & $1.69(0.76-3.78)$ & 46 & $1.43(1.06-1.92)$ \\
Other respiratory diseases & 2 & $1.84(0.46-7.41)$ & 16 & $1.56(0.94-2.60)$ \\
Formaldehyde & & & & \\
All causes of death & 33 & $1.20(0.85-1.68)$ & 2,138 & $1.17(1.11-1.24)$ \\
All respiratory disease & 3 & $1.95(0.63-6.06)$ & 94 & $1.42(1.15-1.75)$ \\
Pneumonia \& influenza & 2 & $4.91(1.22-19.70)$ & 25 & $1.25(0.84-1.88)$ \\
Obstructive lung diseases & 0 & 0.00 & 52 & $1.49(1.12-1.98)$ \\
Other respiratory diseases & 1 & $3.59(0.50-25.58)$ & 17 & $1.47(0.90-2.41)$ \\
\hline
\end{tabular}

* Relative risk and confidence intervals are derived from Poisson regression and are adjusted for age and smoking status. The reference population is composed of 317,424 male study participants who did not report employment in a wood occupation or regular exposure to wood dust.

Table II presents the RRs for the major respiratory disease categories for woodworkers according to selfreported exposure to wood dust, asbestos, or formaldehyde; all comparisons utilize the common reference population of non-exposed/non-woodworkers. Fifty-five percent $(\mathrm{n}=$ 6,319 ) of the woodworkers reported being regularly exposed to wood dust. Thirteen percent $(\mathrm{n}=1,480)$ reported exposure to asbestos, while only $3.3 \%(\mathrm{n}=387)$ reported exposure to formaldehyde. There was some overlap in exposures; 1,194 woodworkers $(10 \%)$ reported both wood dust and asbestos exposure and 305 (2.6\%) woodworkers reported both wood dust and formaldehyde exposure, but only $151(1.3 \%)$ woodworkers reported exposure to all three.

The RR for all respiratory disease was higher among woodworkers who did not report exposure to wood dust $(\mathrm{RR}=1.52,95 \% \mathrm{CI}=1.18-1.97)$ than those who did $(\mathrm{RR}=1.27,95 \% \mathrm{CI}=0.91-1.77)$ and wood dust exposure did not appear to be associated with any of the respiratory disease categories. While the risk for obstructive lung disease was similar in the two groups, the RR for the unexposed group was higher for pneumonia and influenza and much higher for other respiratory disease.

An excess of respiratory disease was observed among woodworkers reporting exposure to asbestos $(\mathrm{RR}=1.59$, 95\% CI $=0.85-2.96$ ), as well as among those not reporting exposure to asbestos $(\mathrm{RR}=1.43,95 \% \mathrm{CI}=1.15-1.77)$. The risk of both obstructive lung disease and "other" respiratory disease (the category which includes asbestosis) was higher among the asbestos-exposed, but the RRs were based on a small number of exposed cases. An excess of respiratory disease was observed among woodworkers reporting exposure to formaldehyde $(\mathrm{RR}=1.95,95 \% \mathrm{CI}=0.63-6.06$ ), and was also elevated among those not reporting exposure to formaldehyde $(\mathrm{RR}=1.42,95 \% \mathrm{CI}=1.15-1.75)$, but only three respiratory disease deaths were observed among the formaldehyde-exposed workers, making interpretation of the more specific disease categories difficult.

Table III presents RRs by duration of wood dust exposure. Duration of exposure information was missing for approximately $11 \%$ of woodworkers who reported exposure. No clear associations with duration of wood dust exposure were apparent, although the risk for respiratory disease was elevated in the longest duration category $(\mathrm{RR}=1.37,95 \%$ $\mathrm{CI}=0.92-2.06)$. Due to the correlation between age and duration, the majority of cases were observed in the longest duration category. The small number of pneumonia and influenza and "other" respiratory disease deaths observed precluded examination of RRs by duration of exposure. Analyses by duration of asbestos and formaldehyde exposure could not be carried out for the same reason. Of the ten woodworkers who reported asbestos exposure and who died of respiratory disease, five reported 20 or more years of exposure, one reported 10-19 years, one reported $<10$ years, and three did not supply this information. Of the three 
TABLE III. Non-Malignant Respiratory Disease Mortality Among Woodworkers by Duration (Years) of Wood Dust Exposure*

\begin{tabular}{lcccccc} 
Cause of death & Observed & $\begin{array}{c}\text { Less than } \mathbf{1 0} \\
\text { RR (95\% Cl) }\end{array}$ & Observed & $\begin{array}{c}\mathbf{1 0} \text { to } \mathbf{1 9} \text { years } \\
\text { RR (95\% Cl) }\end{array}$ & Observed & $\begin{array}{c}\mathbf{2 0} \text { or more } \\
\text { RR (95\% Cl) }\end{array}$ \\
\hline All causes & 54 & $0.89(0.68-1.16)$ & 78 & $1.18(0.95-1.48)$ & 358 & $1.19(1.08-1.34)$ \\
All respiratory disease & 3 & $0.87(0.28-2.71)$ & 3 & $0.83(0.27-2.58)$ & 24 & $1.37(0.92-2.06)$ \\
Obstructive lung disease & 3 & $1.62(0.52-5.02)$ & 2 & $1.03(0.26-4.12)$ & 13 & $1.36(0.79-2.35)$ \\
\hline
\end{tabular}

*Relative risk and confidence intervals are derived from Poisson regression and are adjusted for age and smoking status. The reference population is composed of 317,424 male study participants who did not report employment in a wood occupation or regular exposure to wood dust.

woodworkers who reported formaldehyde exposure and who died of respiratory disease, two reported $<10$ years of exposure and one did not supply duration information.

Approximately $55 \%$ of respiratory disease cases among woodworkers occurred among persons who reported that they were sick at the time of interview. The addition of an indicator variable for health status into the models from which the RRs in Tables I and II were derived resulted in a small (less than 10\%), but generally consistent reduction in risk. For example, the RR for obstructive lung disease among woodworkers decreased from 1.45 to 1.40 for employment as woodworkers and from 1.43 to 1.31 for exposure to wood dust.

\section{DISCUSSION}

In this study, a small (40\%) excess in overall respiratory disease mortality was observed among woodworkers. Excesses of similar magnitude were observed for all major categories of respiratory disease examined. In an analysis of mortality among workers who participated in the first Cancer Prevention Study of the American Cancer Society (1960-72), small excesses were observed for emphysema $(\mathrm{SMR}=110)$ and pneumonia $(\mathrm{SMR}=145)$, but the results regarding other NMRD were not reported [Stellman and Garfinkel 1984]. One other community-based study, the Zutphen study [Post et al., 1994], also found a 30-40\% excess risk of obstructive lung disease among wood dust exposed workers. Exposure in the Zutphen study was defined using a job-exposure matrix based on job titles.

There are a number of possible reasons that an excess of NMRD has not been observed in industry-based cohort studies. Inclusion of unexposed workers in the study populations of the industry-based studies may be responsible for lower observed risks compared with community-based studies. In addition, all the industry-based studies published thus far have used comparisons with the general population, and the "healthy worker effect" may be particularly strong in respect to respiratory diseases. However, when comparisons were made with blue collar workers in the present study, the relative risks decreased, although smaller excesses of obstruc- tive lung disease and "other" respiratory disease remained. This may be due to some unmeasured confounder associated with class, but the blue-collar workers also have the highest likelihood of exposure to other respiratory hazards, so that they may be over-matched to the study population. All analyses in this article were smoking-adjusted but, in fact, smoking was only a very weak confounder. Although other cohort studies have lacked smoking data, it has been speculated that woodworkers may smoke less than other blue collar populations because of the fire hazard posed by wood dust and subsequent restrictions on smoking in the workplace.

Recall bias was possible in this study due to the short length of follow-up. Adjustment for health status at time of interview did indicate that a bias may have been present which could result in a small overestimate of relative risk. However, this interpretation may be spurious if woodworking is indeed associated with an increased risk of disease (i.e., current health status may be in the causal pathway rather than an indicator of recall bias). In addition, if a strong recall bias was present, one might have expected to see a stronger association with occupational exposures (such as asbestos, a well-recognized hazard). The information regarding specific exposures was self-reported, based on a checklist. Although this may represent an improvement over job title alone, the validity and reliability of data obtained in this manner may be low due to selective recall or differences in each individual's criterion for what constitutes exposure. For example, it might come as a surprise that only 55\% of woodworkers reported regular exposure to wood dust. Individuals reporting exposure to wood dust were younger (57.2 years) than those not reporting exposure (61.6 years), indicating the possibility that the criteria for self-assessed exposure might vary with age; however, the age and smoking-adjusted all cause mortality among individuals reporting and not reporting exposure to wood dust was similar. This study was also limited by the lack of detailed job descriptions or a complete work history.

The excess of respiratory disease mortality observed in this study was not clearly associated with exposure to wood 
dust, formaldehyde, or asbestos. This lack of association may have been due to a number of factors. First, it may be that the exposures actually responsible for the excess have not been measured. For example, the excess of NMRD may have been due to exposure to bioaerosols, wood volatiles, or only to certain types of woods. It may also be that the excess is only associated with high exposures, and that duration is an inadequate surrogate for dose. The crude indicators of exposure used may have obscured the relationship due to misclassification.

In conclusion, this study did observe a clear excess of NMRD mortality among woodworkers. The excess did not appear to be closely related to either wood dust, asbestos, or formaldehyde exposure, as ascertained by self-report. However, some associations may have been obscured due to misclassification of exposure. Although limited by a short follow-up period and crude indicators of exposure, the strengths of this analysis were the ability to compare woodworkers to a similar, healthy population, to examine the risks associated with self-reported exposures, and to adjust for the effects of smoking. Cohort studies with better exposure information are needed to examine the role of wood dust and other exposures in the etiology of chronic respiratory disease among woodworkers.

\section{ACKNOWLEDGMENTS}

The authors thank Drs. Michael Thun and Clark Heath for providing comments on a draft of this article.

\section{REFERENCES}

Acheson ED, Pippard EC, Winter PD (1984): Mortality of English furniture makers. Scand J Work Environ Health 10:211-217.

Breslow NE, Day NE (1987): "Statistical Methods in Cancer Research, Volume II - The Design and Analysis of Cohort Studies." Lyon, France: International Agency for Research on Cancer, IARC Sci. Pub. No. 82.

Chan-Yeung M, Malo JL (1995): Occupational respiratory diseases associated with forest products industries. In Harber P, Schenker M, Balmes J (eds): "Occupational and Environmental Respiratory Diseases." St. Louis: Mosby.

Demers PA, Boffetta P, Kogevinas M, Blair A, Miller B, Robinson C, Roscoe R, Winter P, Colin D, Matos E, Vainio H (1995): A pooled re-analysis of cancer mortality among five cohorts of workers in woodrelated industries. Scand J Work Environ Health 21:179-190.

Demers PA, Teschke K, Kennedy SM (1997a). What to do about softwood dust? A review of respiratory effects and recommendations regarding exposure limits. Am J Ind Med 31:385-398.

Demers PA, Boffetta P, Kogevinas M, Colin D, Battista G, Belli S, Blair A, Bolm-Audorf U, Brinton L, Comba P, Guerin M, Hardell L, Hayes R, Leclerc A, Luce D, Magnani C, Merler E, Miller B, Preston-Martin S, Robinson C, Rodella S, Roscoe R, Vainio H, Vaughan T, Winter P, Zheng W (1997b): Pooled analysis of epidemiologic studies of wood dust and cancer. In: "International Agency for Research on Cancer Technical Report No. 30.”' Lyon, France: IARC.

Enarson DA, Chan-Yeung M (1990): Characterization of health effects of wood dust exposures. Am J Ind Med 17:33-38.

Goldsmith DF, Shy CM (1988): Respiratory health effects from occupational exposure to wood dusts. Scand J Work Environ Health 14:1-15.

ILO (1969): "International Standard Classification of Occupations, Revised Edition, 1968." Geneva: International Labour Office.

Post WK, Heederik D, Kromhout H, Kromhout D (1994): Occupational exposures estimated by a population specific job exposure matrix and 25 year incidence rate of chronic nonspecific lung disease (CNSLF): the Zutphen Study. Eur Resp J 7:1048-1055.

Roscoe RJ, Steenland K, McCammon CS, Schober SE, Robinson CF, Halperin WE, Fingerhut MA (1992): Colon and stomach mortality among automotive wood model makers. J Occup Med 34:759-770.

Sluiter HJ, Koeter GH, deMonchy JG, Postma DS, de Vries K, Orie NG (1991): The Dutch hypothesis (chronic nonspecific lung disease) revisited. Eur Resp J 4:479-489.

Stellman SD, Garfinkel L (1984): Cancer mortality among woodworkers. Am J Ind Med 5:343-357.

Stellman SD, Garfinkel L (1986): Smoking habits and tar levels in a new American Cancer Society prospective study of 1,200,000 men and women. J Natl Cancer Inst 76:1057-1063.

Stellman SD, Boffetta P, Garfinkel L (1988): Smoking habits of 800,000 American men and women in relation to their occupations. Am J Ind Med 13:43-58.

Stellman SD, Demers PA, Colin D, Boffetta P (1998): Cancer mortality and wood dust exposure among American Cancer Society Cancer Study II (CPS-II) Participants. Am J Ind Med 34:229-237. 